\title{
Analysis of damping ratio on the optimization of geometrically nonlinear truss structures subjected to dynamic loading
}

\author{
Larissa Bastos Martinelli (Main Author) \\ Department of Civil Engineering - Federal University of Espírito Santo \\ 514 Fernando Ferrari Avenue, VI Technological Center, 204 Room, Vitoria, ES, 29060-970, Brazil \\ larissabastosm@gmail.com \\ https://orcid.org/0000-0002-7232-9986 \\ Élcio Cassimiro Alves (Corresponding Author) \\ Department of Civil Engineering - Federal University of Espírito Santo \\ 514 Fernando Ferrari Avenue, VI Technological Center, 204 Room, Vitoria, ES, 29060-970, Brazil \\ elcio.calves1@gmail.com \\ https://orcid.org/0000-0001-6971-2645
}

Manuscript Code: 13848

Date of Acceptance/Reception: 19.11.2020/17.02.2020

DOI: 10.7764/RDLC.19.3.321

\begin{abstract}
The objective of this paper is to present the formulation for optimizing truss structures with geometric nonlinearity under dynamic loads, provide pertinent case studies and investigate the influence of damping on the final result. The type of optimization studied herein aims to determine the cross-sectional areas that will minimize the weight of a given structural system, by imposing constraints on nodal displacements and axial stresses. The analyses are carried out using Sequential Quadratic Programming (SQP), available in MATLAB's Optimization Toolbox ${ }^{\mathrm{TM}}$. The nonlinear finite space truss element is defined with an updated Lagrangian formulation, and the geometrically nonlinear dynamic analysis performed herein combines the Newmark method with Newton-Raphson iterations. The dynamic analysis approach was validated by comparing the results obtained with solutions available in the literature as well as with numerical models developed with ANSYS ${ }^{\circ} 18.2$. A number of optimization examples of planar and space trusses under dynamic loading with geometric nonlinearity are presented. Results indicate that the consideration of damping effects may lead to a significant reduction in structural weight and that such weight reduction is proportional to increases in damping ratio.
\end{abstract}

Keywords: structural optimization, geometric nonlinearity, dynamic analysis, Damping ratio, trusses.

Introduction

The importance of considering dynamic effects and nonlinear behavior in truss structures has been well established over past decades, and current scientific literature contains numerous research focused on the development of methods to account for such phenomena. Noor \& Peters (1980), for instance, presented a computational procedure for predicting the dynamic response of space trusses considering geometric and material nonlinearities. The study consisted of implementing a mixed formulation to obtain member forces, nodal velocities and nodal displacements of a given structural system. The temporal integration of the governing equations was performed by using an explicit method. Kassimali \& Bidhendi (1988) studied the stability behavior and large deformation response of trusses subjected to dynamic loads. The structural analysis was performed via a combination of Eulerian formulation and the Newmark method. Zhu, Al-Bermani \& Kitipornchai (1994) presented a computational procedure for predicting the geometric and material nonlinear dynamic response of space trusses, using an updated Lagrangian formulation in combination with the Newmark method. Wang et al. (2006) developed a formulation, named the vector form intrinsic finite element (VFIFE or V-5) method, for predicting the nonlinear dynamic behavior of space trusses. The study includes the solution of several numerical examples by using a combination of the newly introduced formulae and an explicit time integration method. More recently, Shi et al. (2015) derived a formulation for the analysis of fully nonlinear truss elements considering geometric and material nonlinearities. The authors presented examples of space trusses subjected to static and dynamic loads to illustrate the application of the new method.

An overview of current scientific literature focused on structural optimization shows numerous studies on trusses, frequently aimed at size optimization of these structures when subjected to static loading. However, said studies usually consider the isolated incidence of either dynamic effects or nonlinear behavior. As examples of the latter, Pyrz (1990) investigated the discrete optimization of elastic trusses with geometric nonlinearity. The study consisted of minimizing the weight of the structure by imposing constraints on element stresses, element stability and global structural stability. Saka \& Ulker (1992) presented a structural optimization algorithm for geometrically nonlinear space trusses subjected to displacement, stress and cross-sectional area constraints. Results show that consideration of nonlinear behavior allows further reduction of overall weight. Suleman \& Sedaghati (2005) developed a structural optimization algorithm for truss and beam structures undergoing large deflections against instability. The authors presented several benchmark 
case studies and compared the results with solutions reported in the literature. Hrinda \& Nguyen (2008) proposed an optimization technique for geometrically nonlinear shallow trusses with snap-through behavior subjected to stability constraints. The authors used the arc length method and a strain energy density approach within a discrete finiteelement formulation.

Alternatively, current literature also provides a number of studies on size optimization of structures subjected to dynamic loading, without considering nonlinear behavior. Ohno et al. (1989) presented a computer-based methodology for minimum weight design of planar trusses subjected to multiple dynamic loads. The method imposes constraints on nodal displacement, stresses and natural frequencies. Chen (1992) proposed a weight optimization procedure using a sequential linear programming technique for the design of structures subjected to static and dynamic displacement constraints. Kocer \& Arora (2002) studied the optimal design of lattice transmission towers subjected to seismic loading. Azad et al. (2018) used the big bang-big crunch algorithm to perform simultaneous size and geometry optimization of steel trusses subjected to dynamic excitations.

As previously mentioned, studies on size optimization of trusses with simultaneous incidence of dynamic and geometric nonlinear effects are seldom observed. However, researches on other types of optimization and structures involving the effects of nonlinear analysis due to dynamic loads can be found in the works by Lee \& Park (2015) and Yan, Cheng \& Wang (2016), where the authors carried out topological optimization studies applied to different structures. Within the same line of study, Alfouneh \& Tong (2018) applied the extended unit load method to study structural nonlinearities due to dynamic loads for topological optimization problems. Cho \& Choi (2000) performed a sensitivity analysis using the finite difference method for structures composed of elastic plastic materials subjected to dynamic loads and subject to large deformations and Kim et al. (2009) analyzed an airplane wing subjected to dynamic loads and the effect of nonlinearities through equivalent static loads.

Moreover, procedures for optimization of structures subjected to dynamic loading usually neglect the effects of damping. As such, the understanding of how this phenomenon influences optimal design remains limited.

Given the lack of research on these subjects, this paper aims to present the formulation for optimizing truss structures with geometric nonlinearity under dynamic loads, provide case studies and investigate the influence of damping on this type of optimization process.

\section{The Optimization Problem}

The type of optimization studied herein aims to determine the cross-sectional areas that will minimize the weight of the structure, by imposing constraints on nodal displacements and axial stresses. As such, the variables of interest are the cross-sectional areas of the bars, contained in vector $\mathbf{A}$, given by Eq. (1).

$$
\mathbf{A}=\left\{\mathrm{A}_{1}, \mathrm{~A}_{2}, \ldots \mathrm{A}_{\mathrm{n}}\right\}
$$

where $n$ represents the total number of bars of the structure. The objective function calculates the structural weight by adding up the weights of each bar, as shown in Eq. (2).

$$
f(A)=\sum_{i=1}^{n} \rho A_{i} L_{i}
$$

where $\rho$ is the density (in $\mathrm{kg} / \mathrm{m}^{3}$ ), $\mathrm{A}_{\mathrm{i}}$ is the cross-sectional area of bar $\mathrm{i}$ and $\mathrm{L}_{\mathrm{i}}$ is the length of bar i. The constraints imposed on the optimization problem are given by Eqs. (3) to (6):

$$
\begin{gathered}
\mathrm{U}_{\text {max }}(\mathbf{A}) \leq \mathrm{U}_{\text {lim }} \\
\sigma_{\mathrm{T}_{\text {max }}}(\mathbf{A}) \leq \sigma_{\mathrm{T}_{\text {lim }}} \\
\sigma_{\mathrm{C}_{\text {max }}}(\mathbf{A}) \leq \sigma_{\mathrm{C}_{\text {lim }}} \\
\mathrm{A}_{\text {min }} \leq \mathrm{A}_{\mathrm{i}} \leq \mathrm{A}_{\text {max }} \quad \mathrm{i}=1, \ldots, \mathrm{n}
\end{gathered}
$$

where $\sigma_{\mathrm{T} \text { max }}$ and $\sigma_{\mathrm{C}_{\max }}$ are the maximum values of tensile and compressive axial stresses developed in the structure, respectively; $\sigma_{\mathrm{T} \text { lim }}$ and $\sigma_{\mathrm{C}_{\text {lim }}}$ are prescribed allowable limits for tensile and compressive stresses; $U_{\max }$ is the maximum absolute value of nodal displacement suffered by the structure; $U_{\text {lim }}$ is the allowable nodal displacement; and $A_{\min }$ and $\mathrm{A}_{\max }$ are the minimum and maximum limits for the design variables. 
In Eqs. (3) to (5), $\mathrm{U}_{\max }, \sigma_{\mathrm{T} \max }$ and $\sigma_{\mathrm{C}_{\max }}$ are nonlinear functions of the design variables, obtained with a geometrically nonlinear dynamic analysis at each iteration of the optimization process. As shown in the following Sections, the nodal displacements of the structure $(\mathbf{U})$ are obtained by solving the equation of motion of the system, which is composed by parameters that depend on the cross-sectional areas of the bars $(\mathbf{A})$, such as mass matrix $(\mathbf{M})$, damping matrix $(\mathbf{C})$ and vector of internal forces $\left(\mathbf{F}_{\mathrm{i}}\right)$. Likewise, the axial stresses of the bars $\left(\sigma_{\mathrm{T}}\right.$ or $\left.\sigma_{\mathrm{C}}\right)$ are obtained by dividing the axial force acting in each bar by its cross-sectional area. In summary, the optimization problem can be expressed by Eq. (7).

$$
\begin{aligned}
& \text { Find } \mathbf{A}=\left\{\mathrm{A}_{1}, \mathrm{~A}_{2}, \ldots \mathrm{A}_{\mathrm{n}}\right\} \\
& \text { that minimizes } \mathrm{f}(\mathbf{A})=\sum_{\mathrm{i}=1}^{\mathrm{n}} \rho \mathrm{A}_{\mathrm{i}} \mathrm{L}_{\mathrm{i}} \\
& \text { subjected to: } \quad\left\{\begin{array}{l}
\mathrm{U}_{\text {max }}(\mathbf{A}) \leq \mathrm{U}_{\mathrm{lim}} \\
\sigma_{\mathrm{T}_{\max }}(\mathbf{A}) \leq \sigma_{\mathrm{T}_{\mathrm{lim}}} \\
\sigma_{\mathrm{C}_{\max }}(\mathbf{A}) \leq \sigma_{\mathrm{C}_{\text {lim }}} \\
\mathrm{A}_{\text {min }} \leq \mathrm{A}_{\mathrm{i}} \leq \mathrm{A}_{\max }
\end{array} \quad \mathrm{i}=1, \ldots, \mathrm{n}\right.
\end{aligned}
$$

To solve this problem, a set of computational routines were executed in MATLAB ${ }^{\oplus}$ R20116a using Sequential Quadratic Programming (SQP) (Spellucci, 1998; Gould \& Toint, 2004), the algorithm of which is available on MATLAB's Optimization Toolbox ${ }^{\mathrm{TM}}$. This method was chosen due to its recurrent use for solving problems with nonlinear constraints, such as the optimization problem in question.

\section{Geometrically Nonlinear Dynamic Analysis}

The governing equation of the problem is the general equation of motion of a structure, given by Eq.(8).

$$
\mathbf{M U ̈}+\mathbf{C} \dot{U}+F_{\mathbf{i}}(\mathbf{U})=\mathbf{F}_{\mathbf{e}}(\mathrm{t})
$$

in which $\ddot{\mathbf{U}}, \dot{\mathbf{U}}$ and $\mathbf{U}$ are the vectors of nodal accelerations, velocities and displacements, respectively; $\mathbf{M}$ is the lumped mass matrix; $\mathbf{C}$ is the damping matrix; $\mathbf{F}_{\mathbf{i}}$ is the vector of internal forces, which depends on nodal displacement vector $\mathbf{U}$; and $\mathbf{F}_{\mathbf{e}}$ is the time-dependent external load vector.

The transient response of the structure is obtained by solving Eq. (8), which involves the use of a time integration algorithm. The procedure shown in this paper for calculating transient response, combines the Newmark method $(\gamma=$ 0.5 and $\beta=0.25$ ) with Newton-Raphson iterations. A flowchart algorithm of said procedure is presented in Figure 1.

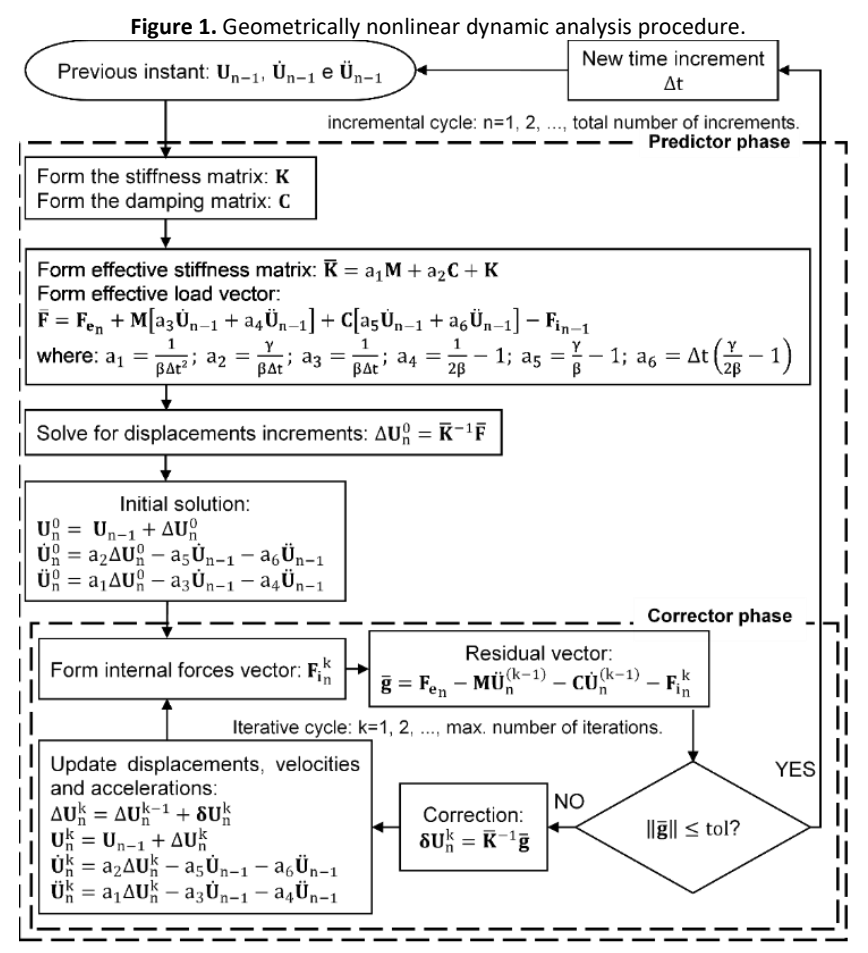

For this paper, the transient responses of interest are the nodal displacements $(\mathbf{U})$ and the axial stresses of the bars $(\sigma)$. The determination of $\mathbf{U}$ is explicitly presented in Figure 1 and the axial stress of a given bar is calculated with Eq. (9). 


$$
\sigma_{\mathrm{n}}=\frac{\mathrm{f}_{\mathrm{Bx}}}{\mathrm{A}}
$$

The variable $\mathrm{f}_{\mathrm{Bx}_{\mathrm{n}}}$ represents the internal force of node $\mathrm{B}$ in the $\mathrm{x}$ direction under configuration $\mathrm{C}_{\mathrm{n}}$, as presented in the following Section; A is the cross-sectional area of the bar and $\sigma_{\mathrm{n}}$ is the axial stress of the bar. Positive values of $\sigma_{\mathrm{n}}$ denote tension $\left(\sigma_{\mathrm{T}}\right)$, while the alternative denotes compression $\left(\sigma_{\mathrm{C}}\right)$.

It is important to emphasize that there are several ways to model damping, but it is usual to consider it to be viscous linear, as done in this paper, because it leads to a simpler mathematical treatment. The damping matrix (C) is proportional to the mass (M) and stiffness (K) matrices, as mathematically expressed by Eq. (10).

$$
\mathbf{C}=\alpha_{0} \mathbf{M}+\alpha_{1} \mathbf{K}
$$

Here, $\alpha_{0}$ and $\alpha_{1}$ are the Rayleigh coefficients, calculated by adopting an appropriate damping ratio (६). Cook, Malkus and Plesha (1989) states that, for steel structures, the ratio varies from $0.5 \%$ to $5 \%$. Definition of the internal force vector $\left(\mathbf{F}_{\mathbf{i}}\right)$ and the stiffness matrix $(\mathbf{K})$ are given in subsequent Sections.

\section{Formulation of the Geometrically Nonlinear Element}

The finite element used in this study consists of a two-node space truss element with the geometry, degrees of freedom and internal forces presented in Figure 2.

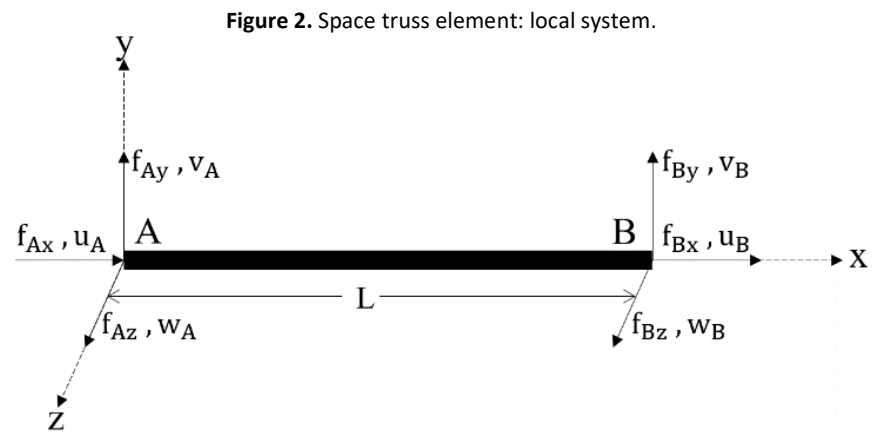

An updated Lagrangian formulation was adopted to describe the motion of this element as summarized subsequentially. For a detailed explanation of the equations depicted here, see Yang and Kuo (1994). The current deformed configuration is denoted by $C_{n}$, and the last known deformed configuration is referred to as $C_{n-1}$. As shown in Figure 3 , element lengths under such configurations are $L_{n}$ and $L_{n-1}$, respectively.

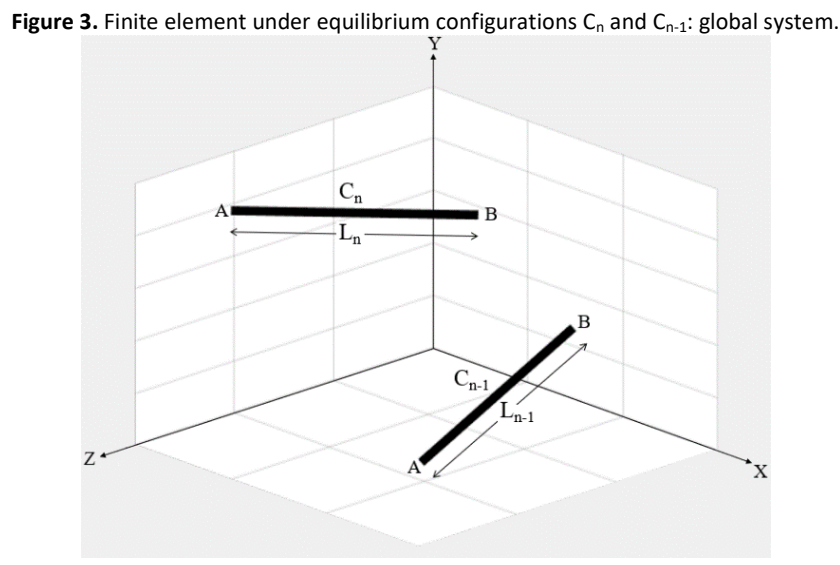


The nodal displacement generated during the incremental step from $C_{n-1}$ to $C_{n}$ is given by Eq. (11).

$$
\mathbf{u}=\left\{\mathrm{u}_{\mathrm{A}} \mathrm{v}_{\mathrm{A}} \mathrm{w}_{\mathrm{A}} \mathrm{u}_{\mathrm{B}} \mathrm{v}_{\mathrm{B}} \mathrm{w}_{\mathrm{B}}\right\}^{\mathrm{T}}
$$

The nodal displacements in the in the $\mathrm{x}, \mathrm{y}$ and $\mathrm{z}$ directions are represented by $\mathrm{u}, \mathrm{v}$ and $\mathrm{w}$, respectively. Correspondingly, the internal forces of the element under the last known deformed configuration $\left(\mathbf{f}_{\mathbf{i}_{n-1}}\right)$ and the current deformed configuration $\left(\mathbf{f}_{\mathbf{i}_{\mathrm{n}}}\right)$ are shown in Eqs. (12) and (13).

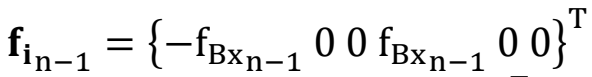

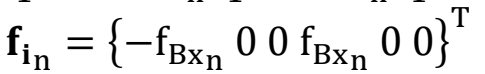

These vectors of internal forces interact with each other, and their relation is described by Eq. (14).

$$
\mathbf{f}_{\mathbf{i}_{\mathrm{n}}}=\left(\mathbf{f}_{\mathbf{i}_{\mathrm{n}-1}}+\Delta \mathbf{f}_{\mathrm{i}}\right) \frac{\mathrm{L}_{\mathrm{n}}}{\mathrm{L}_{\mathrm{n}-1}}
$$

The incremental internal force vector $\Delta \mathbf{f}_{\mathbf{i}}$, is obtained from Eq. (15).

$$
\Delta \mathbf{f}_{\mathbf{i}}=\left\{-\mathrm{EA}\left(\frac{\mathrm{L}_{\mathrm{n}}^{2}-\mathrm{L}_{\mathrm{n}-1}^{2}}{2 \mathrm{~L}_{\mathrm{n}}^{2}}\right) 00 \mathrm{EA}\left(\frac{\mathrm{L}_{\mathrm{n}}^{2}-\mathrm{L}_{\mathrm{n}-1}^{2}}{2 \mathrm{~L}_{\mathrm{n}}^{2}}\right) 00\right\}^{\mathrm{T}}
$$

where $\mathrm{E}$ is the modulus of elasticity and $\mathrm{A}$ is the cross-sectional area. It should be noted that the material is considered linearly elastic. The local stiffness matrix of the element $(\mathbf{k})$ is formed by five components: the elastic stiffness matrix $\left(\mathbf{k}_{\mathrm{e}}\right)$, the geometric stiffness matrix $\left(\mathbf{k}_{\mathrm{g}}\right)$ and the higher-order stiffness matrices $\left(\mathbf{k}_{1}, \mathbf{k}_{2}\right.$ and $\left.\mathbf{k}_{3}\right)$. These matrices are defined by Eqs. (16) trough (22).

$$
\begin{aligned}
& \mathbf{k}=\mathbf{k}_{\mathrm{e}}+\mathbf{k}_{\mathrm{g}}+\mathbf{k}_{1}+\mathbf{k}_{2}+\mathbf{k}_{3} \\
& \mathbf{k}_{\mathrm{e}}=\frac{\mathrm{EA}}{\mathrm{L}_{\mathrm{n}-1}}\left[\begin{array}{cccccc}
1 & 0 & 0 & -1 & 0 & 0 \\
0 & 0 & 0 & 0 & 0 & 0 \\
0 & 0 & 0 & 0 & 0 & 0 \\
-1 & 0 & 0 & 1 & 0 & 0 \\
0 & 0 & 0 & 0 & 0 & 0 \\
0 & 0 & 0 & 0 & 0 & 0
\end{array}\right] \\
& \mathbf{k}_{\mathrm{g}}=\frac{\mathrm{f}_{\mathrm{Bx} n-1}}{\mathrm{~L}_{\mathrm{n}-1}}\left[\begin{array}{cccccc}
1 & 0 & 0 & -1 & 0 & 0 \\
0 & 1 & 0 & 0 & -1 & 0 \\
0 & 0 & 1 & 0 & 0 & -1 \\
-1 & 0 & 0 & 1 & 0 & 0 \\
0 & -1 & 0 & 0 & 1 & 0 \\
0 & 0 & -1 & 0 & 0 & 1
\end{array}\right] \\
& \mathbf{k}_{1}=\frac{\mathrm{EA}}{2 \mathrm{~L}_{\mathrm{n}-1}^{2}}\left[\begin{array}{cccccc}
\Delta \mathrm{u} & \Delta \mathrm{v} & \Delta \mathrm{w} & -\Delta \mathrm{u} & -\Delta \mathrm{v} & -\Delta \mathrm{w} \\
0 & 0 & 0 & 0 & 0 & 0 \\
0 & 0 & 0 & 0 & 0 & 0 \\
-\Delta \mathrm{u} & -\Delta \mathrm{v} & -\Delta \mathrm{w} & \Delta \mathrm{u} & \Delta \mathrm{v} & \Delta \mathrm{w} \\
0 & 0 & 0 & 0 & 0 & 0 \\
0 & 0 & 0 & 0 & 0 & 0
\end{array}\right] \\
& \mathbf{k}_{2}=\frac{\mathrm{EA}}{2 \mathrm{~L}_{\mathrm{n}-1}^{2}}\left[\begin{array}{cccccc}
2 \Delta \mathrm{u} & 0 & 0 & -2 \Delta \mathrm{u} & 0 & 0 \\
\Delta \mathrm{v} & \Delta \mathrm{u} & 0 & -\Delta \mathrm{v} & -\Delta \mathrm{u} & 0 \\
\Delta \mathrm{w} & 0 & \Delta \mathrm{u} & -\Delta \mathrm{w} & 0 & -\Delta \mathrm{u} \\
-2 \Delta \mathrm{u} & 0 & 0 & 2 \Delta \mathrm{u} & 0 & 0 \\
-\Delta \mathrm{v} & -\Delta \mathrm{u} & 0 & \Delta \mathrm{v} & \Delta \mathrm{u} & 0 \\
-\Delta \mathrm{w} & 0 & -\Delta \mathrm{u} & \Delta \mathrm{w} & 0 & \Delta \mathrm{u}
\end{array}\right] \\
& \mathbf{k}_{3}=\frac{E A}{6 L_{\mathbf{n}-1}^{3}}\left[\begin{array}{cc}
\mathbf{h} & -\mathbf{h} \\
-\mathbf{h} & \mathbf{h}
\end{array}\right] \\
& \mathbf{h}=\left[\begin{array}{ccc}
3 \Delta \mathrm{u}^{2}+\Delta \mathrm{v}^{2}+\Delta \mathrm{w}^{2} & 2 \Delta \mathrm{u} \Delta \mathrm{v} & 2 \Delta \mathrm{u} \Delta \mathrm{w} \\
2 \Delta \mathrm{u} \Delta \mathrm{v} & 3 \Delta \mathrm{v}^{2}+\Delta \mathrm{u}^{2}+\Delta \mathrm{w}^{2} & 2 \Delta \mathrm{v} \Delta \mathrm{w} \\
2 \Delta \mathrm{u} \Delta \mathrm{w} & 2 \Delta \mathrm{v} \Delta \mathrm{w} & 3 \Delta \mathrm{w}^{2}+\Delta \mathrm{v}^{2}+\Delta \mathrm{u}^{2}
\end{array}\right]
\end{aligned}
$$


Within each matrix, $\Delta \mathrm{u}=\mathrm{u}_{\mathrm{B}}-\mathrm{u}_{\mathrm{A}}, \Delta \mathrm{v}=\mathrm{v}_{\mathrm{B}}-\mathrm{v}_{\mathrm{A}}$ and $\Delta \mathrm{w}=\mathrm{w}_{\mathrm{B}}-\mathrm{w}_{\mathrm{A}}$. The stiffness matrix and the vector of internal forces of the element can be represented in the global system by Eqs. (23) and (24):

$$
\begin{gathered}
\mathbf{k}_{\text {global }}=\mathbf{T}^{\mathrm{T}} \mathbf{k T} \\
\mathbf{f}_{\mathbf{i}_{\text {global }}}=\mathbf{T}^{\mathrm{T}} \mathbf{f}_{\mathbf{i}}
\end{gathered}
$$

where $\mathbf{T}$ is the transformation matrix. Finally, the stiffness matrix $(\mathbf{K})$ of the global system is the combination of the stiffness matrices of each element. Likewise, the vector of internal forces of the structure $\left(\mathbf{F}_{\mathbf{i}}\right)$ is obtained by combining the internal force vectors of each element.

Numerical Results

Six examples are presented in this Section. The first two consist of implementing the analysis procedure outlined in this paper to calculate the transient response of space trusses. To validate the geometrically nonlinear dynamic analysis, results obtained are compared with solutions available in the literature and with a finite element model generated in ANSYS $^{\circ}$ 18.2. The third example is a case study available in the literature, which is evaluated with the optimization routine. In the three following examples, the optimization routine is applied to the problem statement presented in this paper. For these last examples, the lower and upper limits chosen for the design variables are $3.04 \mathrm{~cm}^{2}$ and $260 \mathrm{~cm}^{2}$, respectively; the allowable values of nodal displacements were established as a fraction of the span of the structure, based on ABNT NBR 8800 (2008); and the limiting values allowed for stresses are defined by Eq. (25).

$$
\sigma_{\mathrm{T}_{\text {lim }}}=\sigma_{\mathrm{C}_{\mathrm{lim}}}=\frac{\mathrm{f}_{\mathrm{y}}}{\gamma_{\mathrm{a} 1}}
$$

In Eq. (25), $\mathrm{f}_{\mathrm{y}}$ is the yield stress, and $\gamma_{\mathrm{a} 1}$ is a reduction coefficient equal to 1.1. For the sake of simplicity, the same stress limit is adopted for both tension and compression. This choice, however, neglects the onset of instability phenomena. The same mechanical properties are adopted in all three last optimization examples: $\mathrm{f}_{\mathrm{y}}=250 \mathrm{MPa}, \mathrm{E}=200 \mathrm{GPa}$ and $\rho=7850 \mathrm{~kg} / \mathrm{m}^{3}$. To evaluate the influence of damping on the optimization process, each example considered an undamped case as well as six other damping ratios.

\section{Example 1: Geodesic Dome - Validation of the Geometrically Nonlinear Dynamic Analysis}

This example considers a geodesic dome with 24 bars and 13 nodes, shown in Figure 4a. Nodes 1 to 7 are unrestrained while nodes 8 through 13 are fixed. All bars have $E=68992 \mathrm{MPa}, \rho=2760 \mathrm{~kg} / \mathrm{m}^{3}$ and $\mathrm{A}=6.45 \mathrm{~cm}^{2}$. The structure is subjected to the transient load shown in Figure $4 \mathrm{~b}$ with $\mathrm{P}=8.9 \mathrm{kN}$ and $\mathrm{T}_{d}=0.01 \mathrm{~s}$.

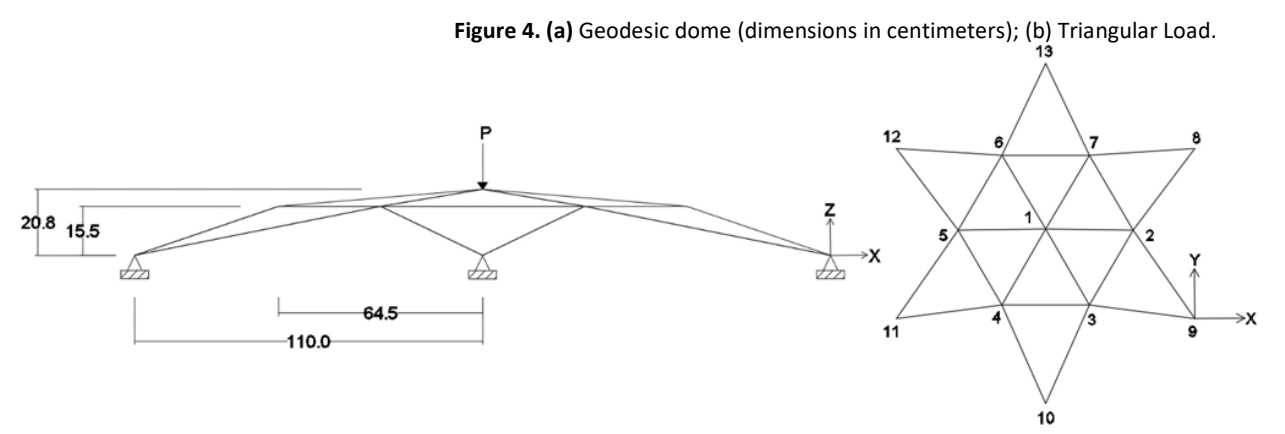

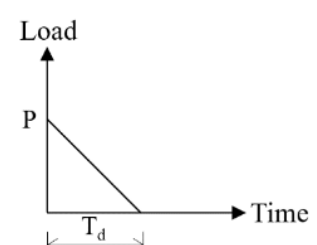

(b)

(a)

This same case was previously studied by Zhu, Al-Bermani \& Kitipornchai (1994) and Wang et al. (2006). As such, the same time step $\Delta t=1.56 \times 10^{-4} \mathrm{~s}$ and damping ratio $\xi=0 \%$ are reproduced in this analysis. Figure 5 shows good agreement between the transient response of node 1 obtained in this paper, and the one presented in the aforementioned literature.

\section{Example 2: Lattice Beam - Validation of the Geometrically Nonlinear Dynamic Analysis}

Figure 6a shows a lattice beam with 76 bars and 28 nodes, and Figure $6 \mathrm{~b}$ shows the load used in this analysis $(P=50$ $\mathrm{kN})$. Mechanical properties were fixed for all bars, with $\mathrm{E}=71700 \mathrm{MPa}$, and $\rho=4152 \mathrm{~kg} / \mathrm{m}^{3}$. However, three groups 
with distinct cross-sectional areas are considered. For group $1, \mathrm{~A}=0.8 \mathrm{~cm}^{2}$, group 2 has $\mathrm{A}=0.6 \mathrm{~cm}^{2}$ and group $3, \mathrm{~A}=$ $0.4 \mathrm{~cm}^{2}$. Nodes $1,7,8,14,15,21,22$ and 28 are fixed.

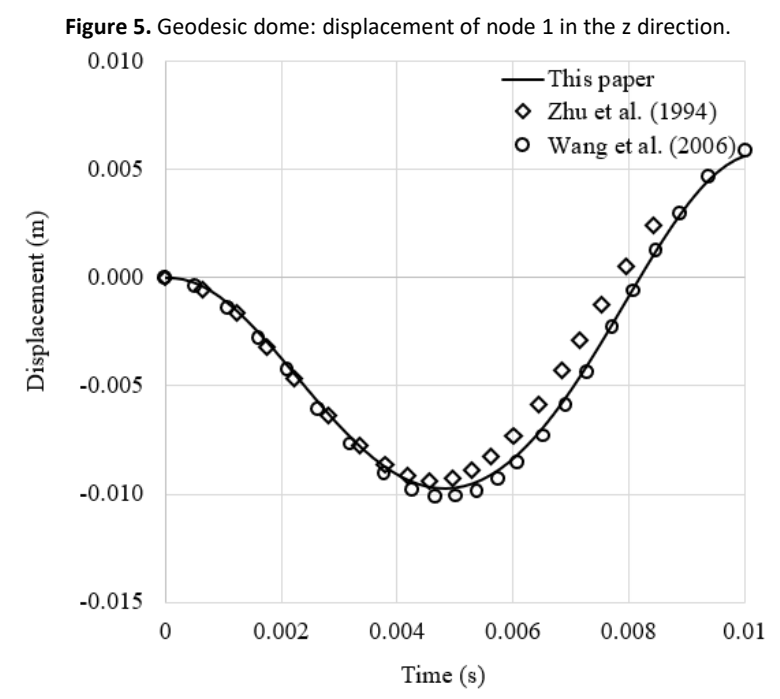

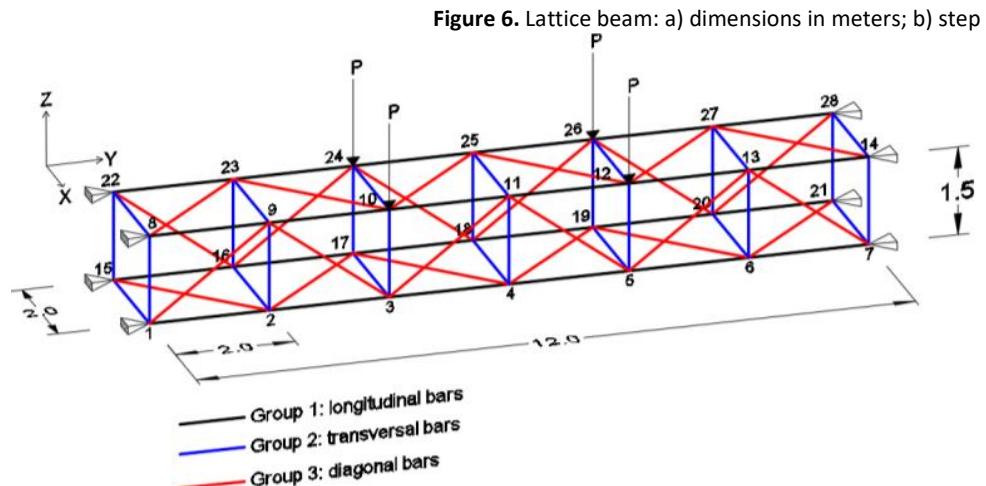

(a)

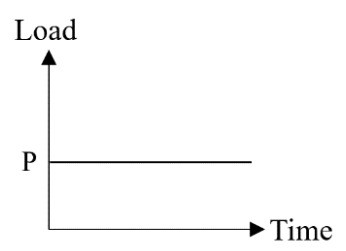

(b)

A time step of $\Delta \mathrm{t}=10^{-5} \mathrm{~s}$ was used in the geometrically nonlinear dynamic analysis. Figure 7, compares the transient response of node 10 with the one obtained with ANSYS $^{\oplus}$ 18.2. Acceptable agreement is observed for $\xi=0 \%$ and $\xi=5 \%$.

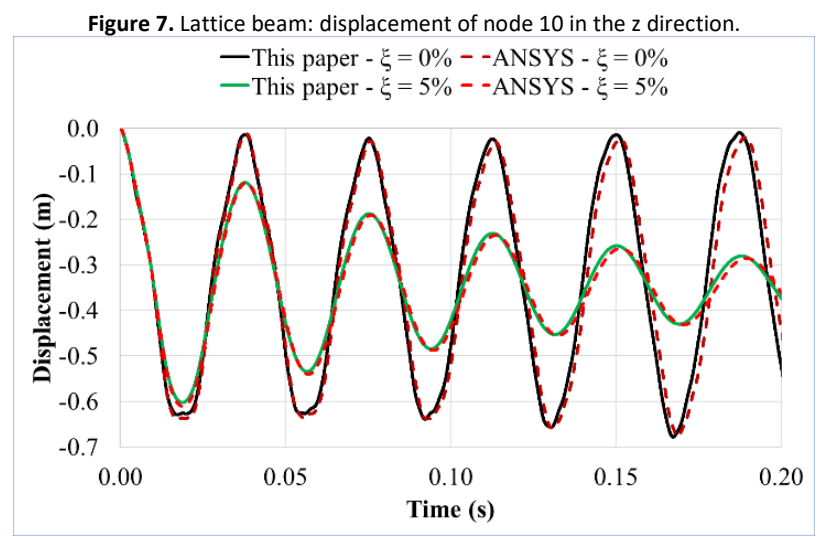

\section{Example 3: Planar truss with ten bars - Compared optimization}

This example consists of a planar truss with 10 bars and 6 nodes. Figure 8a shows its geometry, loading and boundary conditions. All bars have $\rho=7860 \mathrm{~kg} / \mathrm{m}^{3}, \mathrm{~A}=3.14 \mathrm{~cm}^{2}$ and $\mathrm{f}_{\mathrm{y}}=200 \mathrm{MPa}$. The structure is subjected to the dynamic load presented in Figure $8 \mathrm{~b}$. 


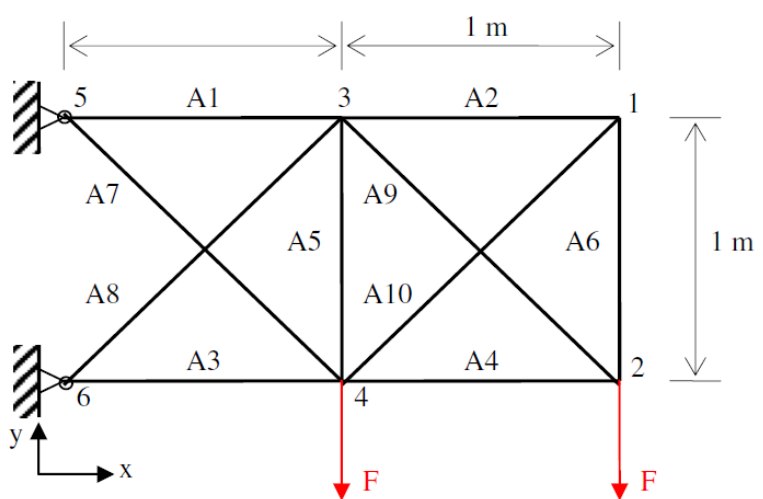

(a)

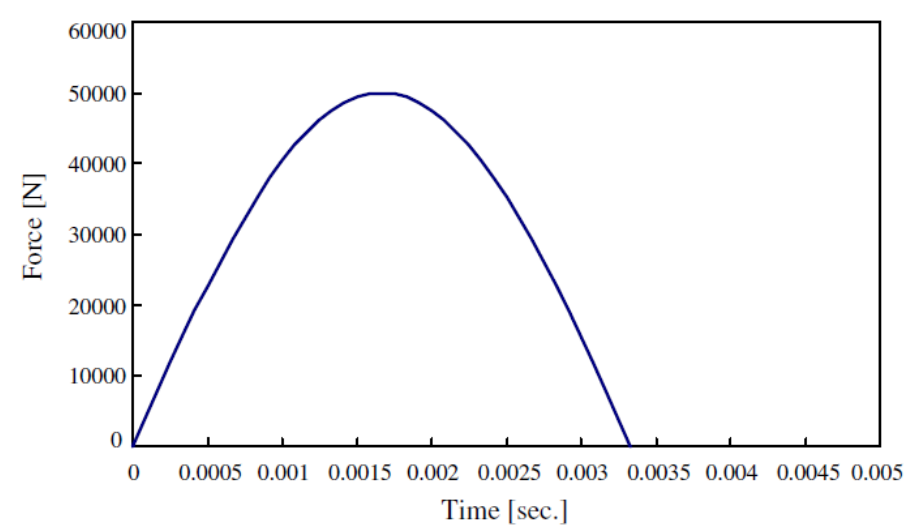

(b)

This same case was previously studied by Kim \& Park (2010). In the original example, the authors studied the material nonlinearity of the structure, considering a bilinear elastoplastic strain-stress curve, with Young's modulus of $200 \mathrm{GPa}$ and tangent modulus of $50 \mathrm{GPa}$. In this paper, the structure is considered geometrically nonlinear and the material is linear elastic, with $\mathrm{E}=50 \mathrm{GPa}$.

The same parameters used by Kim \& Park (2010) are reproduced in this paper: limiting value for tensile and compressive stresses is $250 \mathrm{MPa}$; lower and upper limits for the design variables are $0.785 \mathrm{~cm}^{2}$ and $28.26 \mathrm{~cm}^{2}$, respectively; duration time of the dynamic load is $0.0033 \mathrm{~s}$; total analysis time is $0.03 \mathrm{~s}$; time step is $0.0002 \mathrm{~s}$; and damping ratio $\xi=0 \%$. The initial design and the optimization results obtained are shown in Table 1.

\begin{tabular}{cccc}
\multicolumn{4}{c}{ Table 1. Initial design and optimization results for the planar truss. } \\
\hline & Initial design & \multicolumn{2}{c}{ Optimization results } \\
\cline { 3 - 4 } & & Kim and Park (2010) & This paper \\
\hline A1 $\left(\mathrm{cm}^{2}\right)$ & 3.14 & 4.976 & 4.1327 \\
A2 $\left(\mathrm{cm}^{2}\right)$ & 3.14 & 0.955 & 1.9422 \\
A3 $\left(\mathrm{cm}^{2}\right)$ & 3.14 & 4.806 & 5.1792 \\
A4 $\left(\mathrm{cm}^{2}\right)$ & 3.14 & 1.569 & 1.0745 \\
A5 $\left(\mathrm{cm}^{2}\right)$ & 3.14 & 0.786 & 4.6656 \\
A6 $\left(\mathrm{cm}^{2}\right)$ & 3.14 & 0.786 & 2.8912 \\
A7 $\left(\mathrm{cm}^{2}\right)$ & 3.14 & 3.163 & 3.6533 \\
A8 $\left(\mathrm{cm}^{2}\right)$ & 3.14 & 3.368 & 2.0882 \\
A9 $\left(\mathrm{cm}^{2}\right)$ & 3.14 & 2.099 & 1.1152 \\
A10 $\left(\mathrm{cm}^{2}\right)$ & 3.14 & 1.138 & 1.8695 \\
Weight $(\mathrm{kg})$ & 28.77 & 21.77 & 25.33 \\
$\sigma_{\text {max }}(\mathrm{MPa})$ & 323.7 & 249 & 250 \\
\hline
\end{tabular}

As previously mentioned, Kim \& Park (2010) studied a different type of nonlinearity than the one adopted in this paper. Therefore, it was expected that the results obtained were not the same. However, comparing both results allows to observe the influence of each nonlinearity in this case study. Kim \& Park (2010) considered material nonlinearity and achieved a weight reduction of $24.33 \%$, while the procedure used in this paper for geometrical nonlinearity resulted in a structure only $11.96 \%$ lighter than the initial design. Thus, studying this example considering material nonlinearity leads to almost double weight reduction than considering geometrical nonlinearity.

\section{Example 4: Geodesic Dome - Optimization}

In this case the optimization procedure is applied to the geodesic dome of Example 1 . The geometry and load profile presented in Figure 4 are reproduced here. However, for this case $f_{y}=250 \mathrm{MPa}, \mathrm{E}=200 \mathrm{GPa}, \rho=7850 \mathrm{~kg} / \mathrm{m}^{3}, \mathrm{P}=$ $356 \mathrm{kN}$ and $\mathrm{Td}=0.1 \mathrm{~s}$. Three groups of bars are considered, as shown in Figure 9. 


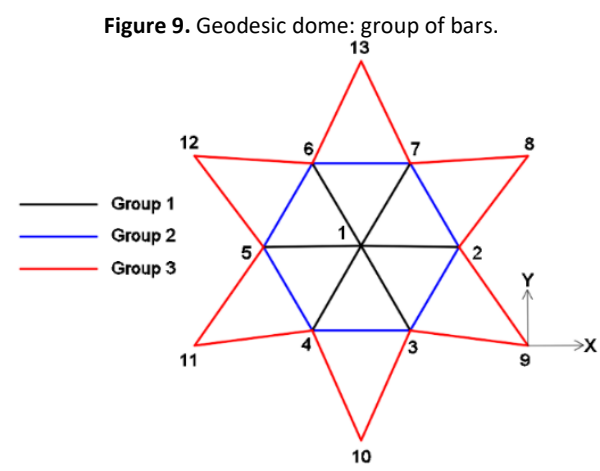

The limiting value of nodal displacement was fixed at $0.007 \mathrm{~m}$, while the limit for tensile and compressive stresses was set at $227 \mathrm{MPa}$. For the dynamic analysis performed in the optimization process, a duration of $0.1 \mathrm{~s}$ and a time step $\Delta \mathrm{t}$ $=0.0001 \mathrm{~s}$ were adopted. The initial design and the optimization results obtained for different values of damping ratio are shown in Table 2.

Table 2. Initial design and optimization results for the geodesic dome.

\begin{tabular}{|c|c|c|c|c|c|c|c|c|}
\hline & \multirow{2}{*}{$\begin{array}{l}\text { Initial } \\
\text { design }\end{array}$} & \multicolumn{7}{|c|}{ Optimization results } \\
\hline & & $\xi=0 \%$ & $\xi=0.5 \%$ & $\xi=1 \%$ & $\xi=2 \%$ & $\xi=3 \%$ & $\xi=4 \%$ & $\xi=5 \%$ \\
\hline $\mathrm{A} 1\left(\mathrm{~cm}^{2}\right)$ & 260 & 193.5808 & 189.8994 & 188.4265 & 185.6098 & 182.9248 & 180.3367 & 177.8271 \\
\hline $\mathrm{A} 2\left(\mathrm{~cm}^{2}\right)$ & 260 & 177.4242 & 191.6735 & 189.6515 & 185.7113 & 181.9262 & 178.3112 & 174.8597 \\
\hline $\mathrm{A} 3\left(\mathrm{~cm}^{2}\right)$ & 260 & 22.3056 & 16.2275 & 16.5639 & 17.1837 & 17.7396 & 18.2374 & 18.6856 \\
\hline Weight (kg) & $\begin{array}{c}3532.857 \\
7\end{array}$ & $\begin{array}{c}1296.676 \\
4\end{array}$ & $\begin{array}{c}1283.164 \\
0\end{array}$ & $\begin{array}{c}1275.052 \\
2\end{array}$ & $\begin{array}{c}1259.139 \\
1\end{array}$ & $\begin{array}{c}1243.619 \\
8\end{array}$ & $\begin{array}{c}1228.477 \\
3\end{array}$ & 1213.6991 \\
\hline $\mathrm{U}_{\max }(\mathrm{m})$ & - & 0.007 & 0.007 & 0.007 & 0.007 & 0.007 & 0.007 & 0.007 \\
\hline$\sigma_{\mathrm{T}_{\max }}(\mathrm{MPa})$ & - & 91.2696 & 101.7165 & 78.2718 & 56.5276 & 56.7036 & 56.9169 & 57.1421 \\
\hline$\sigma_{\mathrm{C}_{\max }}(\mathrm{MPa})$ & - & 161.0229 & 213.7410 & 207.8548 & 197.2475 & 187.9259 & 179.676 & 172.3087 \\
\hline $\begin{array}{l}\text { Number of } \\
\text { iterations }\end{array}$ & - & 46 & 31 & 39 & 32 & 37 & 31 & 24 \\
\hline $\begin{array}{l}\text { Number of objective } \\
\text { function evaluations }\end{array}$ & - & 458 & 216 & 303 & 238 & 326 & 341 & 191 \\
\hline
\end{tabular}

The comparative graph in Figure 10, indicates that variation of damping does not result in a significant reduction in weight. With $\xi=0.5 \%$, the structure is only $1 \%$ lighter than the undamped case, likely due to the high rigidity of the structure. When the damping ratio is increased to $1 \%$, the structure becomes $0.6 \%$ lighter in comparison with $\xi=0.5 \%$. Additional increments of damping ratio, up to $5 \%$, all indicate a weight reduction of $1.2 \%$ in relation to each previous increment.

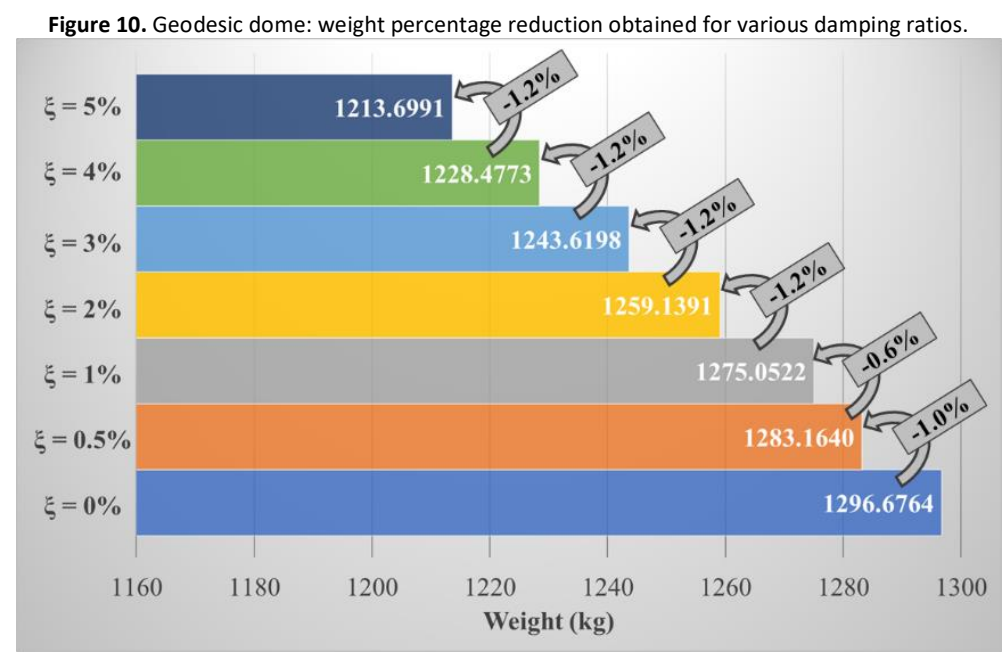




\section{Example 5: Lattice Beam - Optimization}

Analogously to the previous example, the second optimization study reproduces the geometry, general load profile and groups of bars from Example 2. For this example, however, $\mathrm{f}_{\mathrm{y}}=250 \mathrm{MPa}, \mathrm{E}=200 \mathrm{GPa}, \rho=7850 \mathrm{~kg} / \mathrm{m}^{3}$ and $\mathrm{P}=100$ $\mathrm{kN}$. The limit value of nodal displacement was set at $0.034 \mathrm{~m}$ and stresses are constrained to $227 \mathrm{MPa}$. A duration of 0.5 $\mathrm{s}$ and a time step $\Delta \mathrm{t}=0.001 \mathrm{~s}$ are adopted for the dynamic analysis. The initial design and the optimization results obtained for different values of damping ratio are shown in Table 3.

Table 3. Initial design and optimization results for the latticed beam.

\begin{tabular}{ccccccccc}
\multicolumn{10}{c}{ Table 3. Initial design and optimization results for the latticed beam. } \\
\cline { 3 - 9 } & Initial & \multicolumn{7}{c}{ Optimization results } \\
\cline { 3 - 9 } & design & $\xi=0 \%$ & $\xi=0.5 \%$ & $\xi=1 \%$ & $\xi=2 \%$ & $\xi=3 \%$ & $\xi=4 \%$ & $\xi=5 \%$ \\
\hline A1 $\left(\mathrm{cm}^{2}\right)$ & 260 & 22.4222 & 15.3036 & 15.1937 & 15.0009 & 14.8071 & 14.6117 & 14.4168 \\
$\mathrm{~A} 2\left(\mathrm{~cm}^{2}\right)$ & 260 & 7.7398 & 7.2404 & 7.0456 & 6.6952 & 6.3997 & 6.1557 & 5.9663 \\
$\mathrm{~A} 3\left(\mathrm{~cm}^{2}\right)$ & 260 & 19.3697 & 16.0712 & 15.8582 & 15.4489 & 15.068 & 14.7177 & 14.3972 \\
Weight $(\mathrm{kg})$ & 32848.0837 & 2114.8170 & 1661.8152 & 1639.4898 & 1598.1998 & 1560.4130 & 1526.0832 & 1495.3670 \\
$\mathrm{U}_{\text {max }}(\mathrm{m})$ & - & 0.015043 & 0.019020 & 0.019008 & 0.018993 & 0.018999 & 0.019016 & 0.019035 \\
$\sigma_{\mathrm{T}}$ max \\
$(\mathrm{MPa})$
\end{tabular}

As opposed to neglecting damping effects, Figure 11 shows that the use of a rather small damping ratio such as $0.5 \%$, is enough to generate a significant reduction of weight, of $21 \%$. From this point on, however, variations in damping bear no significant effect on structural weight if compared with each previous increment, with all subsequent weight reductions falling within the range of $1-2 \%$.

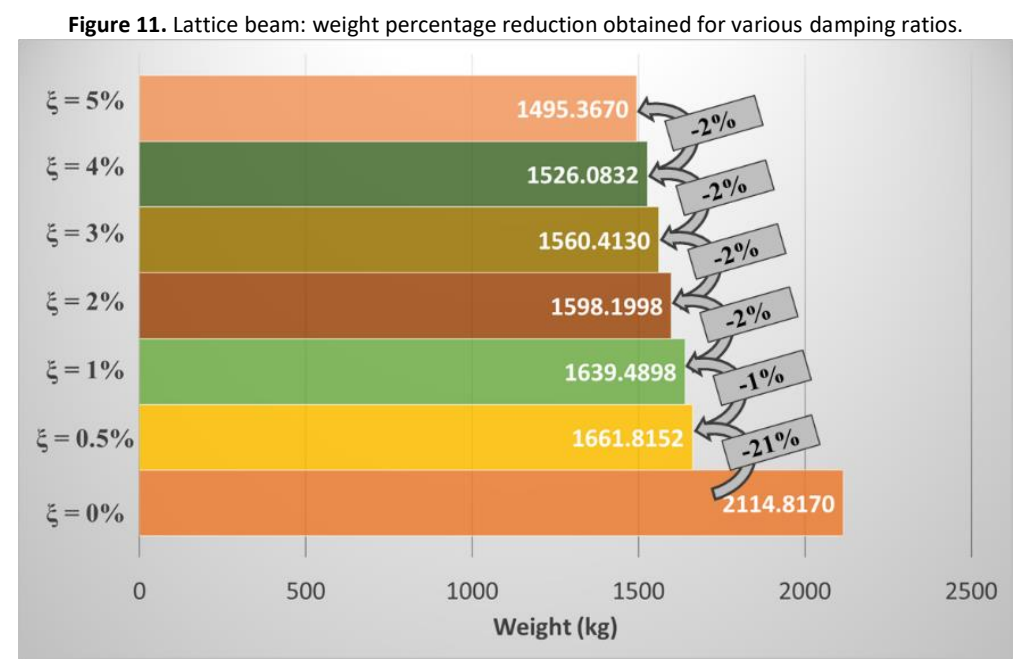

\section{Example 6: Transmission Tower - Optimization}

This example consists of a transmission tower with 47 bars and 22 nodes (Figure 12a). All nodes are free to move with the exception of nodes 21 and 22 which are fixed. The structure is subjected to the general load profile shown in Figure $12 b$, representing the weight of the cables and the wind load acting on the tower. Bar grouping and load values applied to each node are shown in Figure $12 b$.

Limiting values allowed for nodal displacement and all stresses are set at $0.08 \mathrm{~m}$ and $227 \mathrm{MPa}$, respectively. A duration of $1 \mathrm{~s}$ and a time step $\Delta \mathrm{t}=0.01 \mathrm{~s}$ are adopted for the dynamic analysis performed throughout the optimization procedure. 


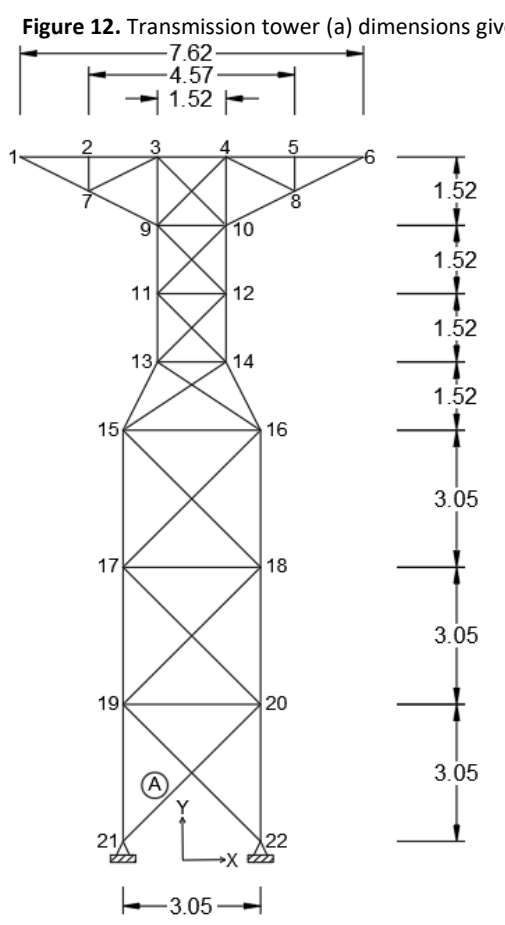

(a)

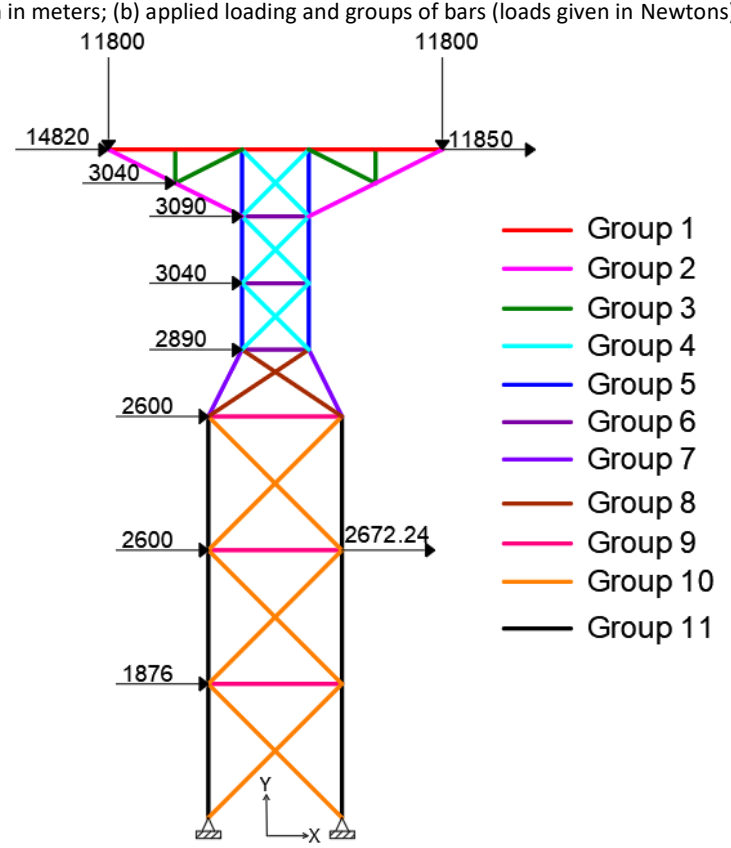

(b)

Table 4 presents the initial design used and the optimization results obtained for different values of damping ratio. The transient response of node 6 after optimization, for all damping ratios, is shown in Figue 13. Figure 14 shows the axial stress of bar A over time.

Table 4. Initial design and optimization results for the transmission tower.

\begin{tabular}{|c|c|c|c|c|c|c|c|c|}
\hline & \multirow{2}{*}{ Initial design } & \multicolumn{7}{|c|}{ Optimization results } \\
\hline & & $\xi=0 \%$ & $\xi=0.5 \%$ & $\xi=1 \%$ & $\xi=2 \%$ & $\xi=3 \%$ & $\xi=4 \%$ & $\xi=5 \%$ \\
\hline $\mathrm{A} 1\left(\mathrm{~cm}^{2}\right)$ & 260 & 10.8159 & 3.0400 & 3.0400 & 3.0400 & 3.0400 & 3.0400 & 3.0400 \\
\hline $\mathrm{A} 2\left(\mathrm{~cm}^{2}\right)$ & 260 & 3.0400 & 3.0400 & 3.0400 & 3.0400 & 3.0400 & 3.0400 & 3.0400 \\
\hline A3 $\left(\mathrm{cm}^{2}\right)$ & 260 & 3.0400 & 3.0400 & 3.0400 & 3.0400 & 3.0400 & 3.0400 & 3.0400 \\
\hline $\mathrm{A} 4\left(\mathrm{~cm}^{2}\right)$ & 260 & 4.8099 & 3.0400 & 3.0400 & 3.0400 & 3.0400 & 3.0400 & 3.0400 \\
\hline $\mathrm{A} 5\left(\mathrm{~cm}^{2}\right)$ & 260 & 10.9227 & 6.3976 & 6.3057 & 6.1223 & 6.0835 & 6.1106 & 6.1368 \\
\hline $\mathrm{A} 6\left(\mathrm{~cm}^{2}\right)$ & 260 & 3.0400 & 3.0400 & 3.0400 & 3.0400 & 3.0400 & 3.0400 & 3.0400 \\
\hline $\mathrm{A} 7\left(\mathrm{~cm}^{2}\right)$ & 260 & 15.6703 & 13.6533 & 13.4943 & 13.1851 & 13.0487 & 12.9892 & 12.9282 \\
\hline $\mathrm{A} 8\left(\mathrm{~cm}^{2}\right)$ & 260 & 4.6436 & 3.8368 & 3.7894 & 3.6949 & 3.6632 & 3.6581 & 3.6524 \\
\hline $\mathrm{A} 9\left(\mathrm{~cm}^{2}\right)$ & 260 & 3.0400 & 3.0400 & 3.0400 & 3.0400 & 3.0400 & 3.0400 & 3.0400 \\
\hline $\mathrm{A} 10\left(\mathrm{~cm}^{2}\right)$ & 260 & 3.6654 & 4.1631 & 4.1654 & 4.1714 & 4.1336 & 4.0754 & 4.0180 \\
\hline $\mathrm{A} 11\left(\mathrm{~cm}^{2}\right)$ & 260 & 19.2338 & 20.2782 & 20.1900 & 20.0230 & 19.8096 & 19.5732 & 19.3391 \\
\hline Weight (kg) & 22076.0900 & 664.9780 & 584.3981 & 581.8902 & 577.0689 & 572.4562 & 567.8903 & 563.3601 \\
\hline $\mathrm{U}_{\max }(\mathrm{m})$ & - & 0.08 & 0.08 & 0.08 & 0.08 & 0.08 & 0.08 & 0.08 \\
\hline$\sigma_{\mathrm{T}_{\text {max }}}(\mathrm{MPa})$ & - & 193.5679 & 183.6943 & 182.0174 & 178.6671 & 177.5891 & 177.5664 & 177.5423 \\
\hline$\sigma_{\mathrm{C}_{\max }}(\mathrm{MPa})$ & - & 201.6504 & 214.3881 & 205.1776 & 208.0514 & 208.3433 & 206.3747 & 204.4334 \\
\hline $\begin{array}{l}\text { Number of } \\
\text { iterations }\end{array}$ & - & 152 & 60 & 55 & 78 & 43 & 50 & 39 \\
\hline $\begin{array}{l}\text { Number of } \\
\text { objective function } \\
\text { evaluations }\end{array}$ & - & 2100 & 891 & 822 & 1248 & 605 & 707 & 550 \\
\hline
\end{tabular}



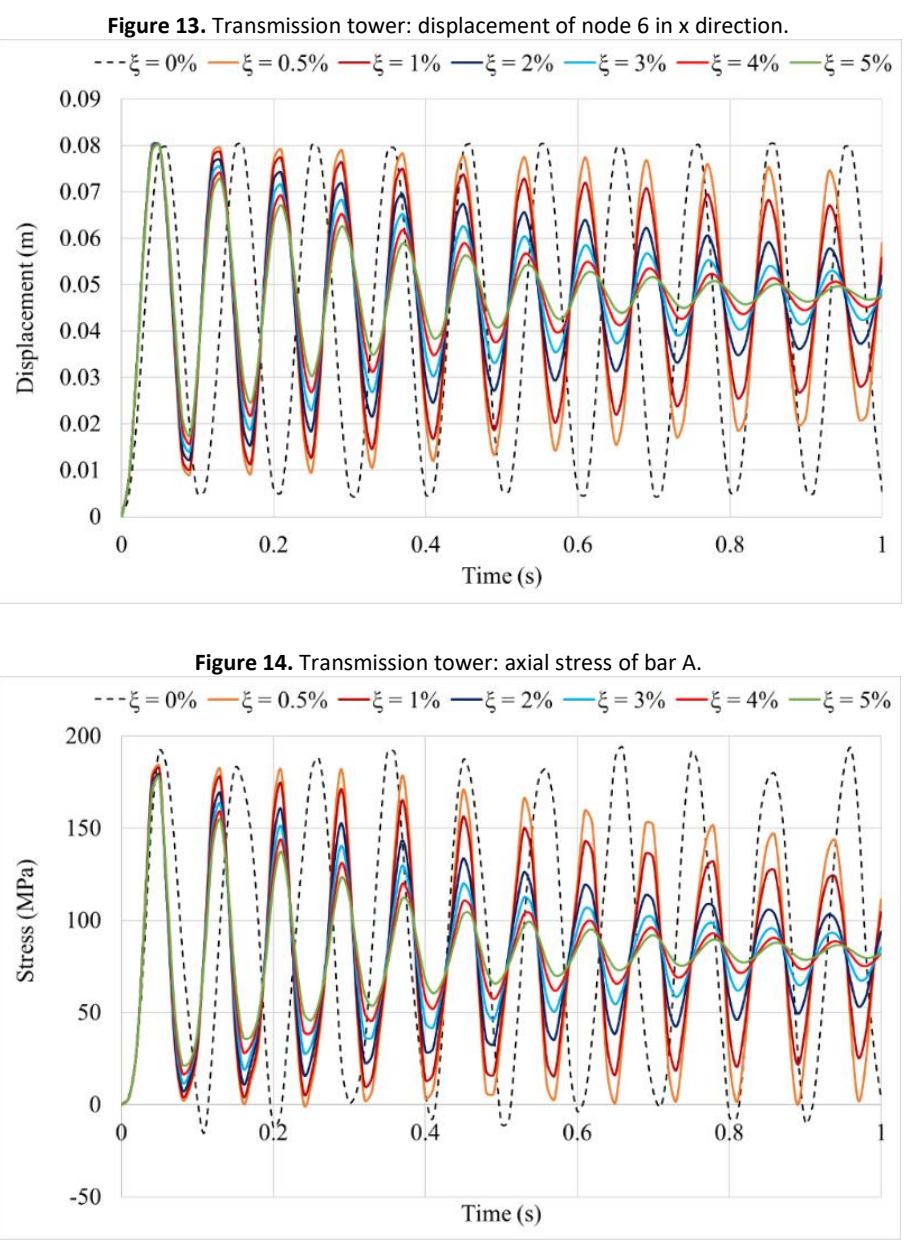

In a manner similar to Example 5, Figure 15 indicates that the consideration of a $0.5 \%$ damping ratio results in significant weight reduction, $12.1 \%$ in this case. Furthermore, in accordance with results obtained in all previous optimization examples, it seems that further increments in damping ratio cease to significantly affect structural weight.

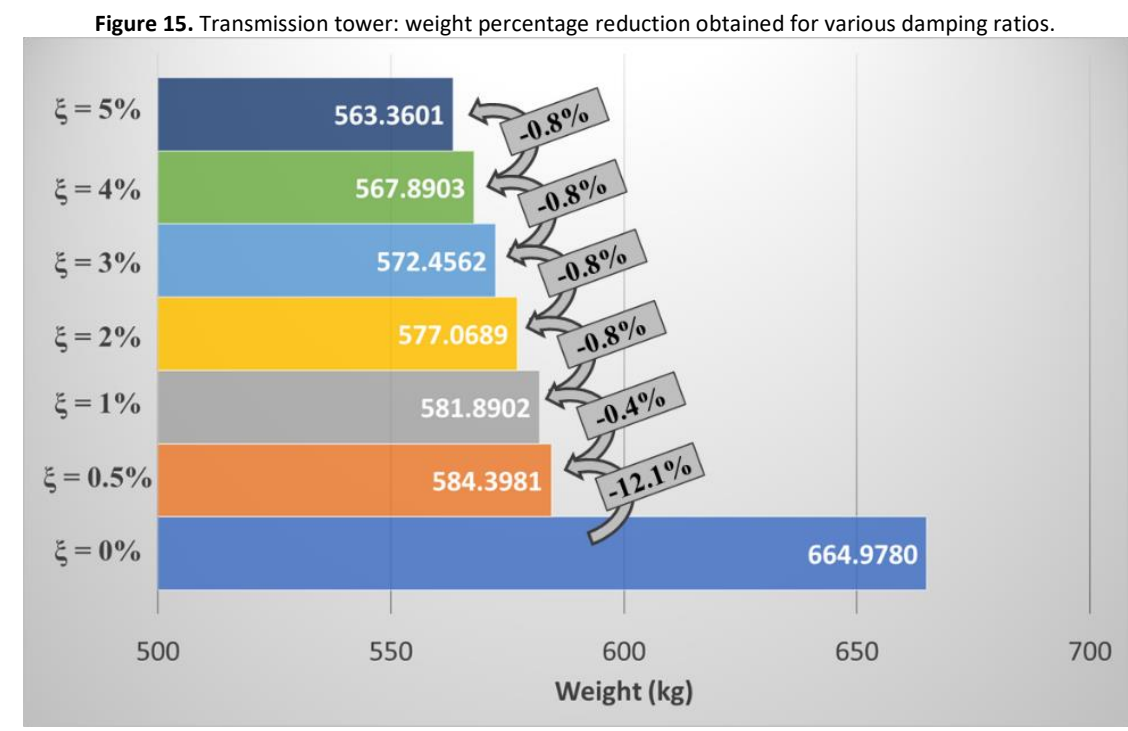

In this paper, a set of computational routines were performed in MATLAB to study the optimization of geometrically nonlinear truss structures subjected to dynamic loading, using the SQP algorithm available on MATLAB's Optimization Toolbox $^{\mathrm{TM}}$. The formulated optimization problem sought to determine the cross-sectional areas that would minimize the weight of the structure, imposing constraints on nodal displacements and axial stresses. 
As these constraints imply the necessity to perform a geometrically nonlinear dynamic analysis at each iteration of the optimization process, the first two examples were dedicated to validating the analysis procedure. The transient response of the space trusses was calculated, and the results obtained were consistent with solutions available in the literature and with results generated by ANSYS ${ }^{\circledR}$ 18.2. Therefore, the analysis procedure is considered validated.

In Example 3, an optimization case study available in the literature was evaluated, comparing the influence of different nonlinear behaviors. Results showed that considering material nonlinearity may lead to almost double weight reduction than considering geometrical nonlinearity.

In Examples 4 to 6, the optimization process was used in order to study space and planar trusses. Results showed a significant reduction of weight if damping is accounted for in the second and third examples. As opposed to neglecting damping effects, the consideration of a damping ratio of $\xi=0.5 \%$ resulted in $21 \%$ weight reduction of the lattice beam and $12.1 \%$ of the transmission tower. However, in the first example this reduction of weight was not as substantial. The geodesic dome exhibits a structural weight reduction of just $1 \%$ with $\xi=0.5 \%$ when compared with $\xi=0 \%$. This is likely due to the higher rigidity of the geodesic dome in comparison with the other two structures.

Furthermore, it was observed that in all three last optimization examples, the increase of damping ratio was proportional to the reduction of weight. A $0.5 \%$ increment in $\xi$ on the geodesic dome (from $\xi=0.5 \%$ to $\xi=1 \%$ ) caused a reduction of weight of $0.6 \%$. Subsequentially, doubling the increase in damping ratio also caused the reduction in weight to double to $1.2 \%$. The remaining optimization studies also show analogous responses starting at the second damping ratio increment of $\xi=0.5 \%$ to $\xi=1 \%$. Further increases of $1 \%$ in $\xi$ doubled the weight reduction of the lattice beam from $1 \%$ to $2 \%$, while the transmission tower shows a difference from $0.4 \%$ to $0.8 \%$ in weight within the same range of damping ratio values.

\section{Acknowledgements}

The authors would like to acknowledge the financial support provided by CAPES (Coordination for the Improvement of Higher Education Personnel).

References

ABNT NBR 8800: Design of Steel and Composite Structures for Buildings. Rio de Janeiro (2008)

Alfouneh, M., Tong, L. (2018). Topology optimization of nonlinear structures with damping under arbitrary dynamic loading. Struct. Multidisc. Optim., 57, 759-774. doi: 10.1007/s00158-017-1765-6

Azad, S. K., Bybordiani, M., Azad, S. K., Jawad, F. K. J. (2018). Simultaneous size and geometry optimization of steel trusses under dynamic excitations. Struct. Multidiscip. Optim., 58, 2545-2563.

Chen, T. -Y. (1992). Design optimization with static and dynamic displacement constraints. Struct. Optim., 4(3-4), 179-185.

Cho, S., Choi, K. K. (2000). Design sensitivity analysis and optimization of nonlinear transient dynamics. Part I-sizing design. Int. J. Numer. Methods Engrg., 48, 351-373.

Cook, R. D., Malkus, D. S., Plesha, M. E. (1989). Concepts and applications of finite element analysis. John Wiley \& Sons.

Gould, N., Toint, P. L. (2004). Preprocessing for quadratic programming. Math. Programming., 100, 95-132.

Hrinda, G. A., Nguyen, D. T. (2008). Optimization of stability-constrained geometrically nonlinear shallow trusses using an arc length sparse method with a strain energy density approach. Finite Elem. Anal. Des., 44(15), 933-950.

Kassimali, A., Bidhendi, E. (1988). Stability of trusses under dynamic loads. Comput. Struct., 29(3), 381-392.

Kim, Y. I., Park, G. J., Kolonay, R. M., Blair, M., Canfield, R. A. (2009). Nonlinear dynamic response structural optimization of a joined-wing using equivalent static loads. J. Aircraft, 46(3), 821-831.

Kim, Y. -I., Park, G. -J. (2010). Nonlinear dynamic response structural optimization using equivalent static loads. Comput. Methods Appl. Mech. Engrg., 199, 660-676.

Kocer, F. Y., Arora, J. S. (2002). Optimal Design of Latticed Towers Subjected to Earthquake Loading. J. Struct. Eng., 128(2), 197-204.

Lee, H. A, Park, G. J. (2015). Nonlinear dynamic response topology optimization using the equivalent static loads method. Comput. Methods Appl. Mech. Engrg., 283, 956-970.

Noor, A. K., Peters, J. M. (1980). Nonlinear dynamic analysis of space trusses. Comput. Methods Appl. Mech. Eng., 21(2), 131-151.

Ohno, T., Kramer, G. J. E., Grierson, D. E. (1989). Least-weight design of frameworks under multiple dynamic loads. Struct. Optim., 1(3), 181-191.

Pyrz, M. (1990). Discrete optimization of geometrically nonlinear truss structures under stability constraints. Struct. Optim., 2(2), $125-131$. 
Saka, M. P., Ulker, M. (1992). Optimum design of geometrically nonlinear space trusses. Comput. Struct., 42(3), 289-299.

Shi, H., Salim, H., Shi, Y., Wei, F. (2015). Geometric and material nonlinear static and dynamic analysis of space truss structures. Mech. Based Des. Struct. Mach., 43, 38-56.

Spellucci, P. (1998). A new technique for inconsistent QP problems in the SQP method. Mathematical Methods of Operations Research, 47(3), 355400 .

Suleman, A., Sedaghati, R. (2005). Benchmark case studies in optimization of geometrically nonlinear structures. Struct. Multidiscip. Optim., 30(4), 273-296.

Wang, C. -Y., Wang, R. -Z., Chuang, C. -C., Wu, T. -Y. (2006). Nonlinear dynamic analysis of reticulated space truss structures. J. Mech., $22(3), 199-212$. Yan, K., Cheng, G., Wang, B. P. (2016). Topology optimization of plate structures subject to initial excitations for minimum dynamic performance index. Struct. Multidiscip. Optim., 53, 623-633.

Yang, Y. -B., Kuo, S. -R. (1994). Theory and analysis of nonlinear framed structures. Prentice Hall, New York.

Zhu, K., Al-Bermani, F. G. A., Kitipornchai, S. (1994). Nonlinear dynamic analysis of lattice structures. Comput. Struct., 52(1), 9-15. 